Salman Bin Mahmood, MBBS

Department of Medicine, Hennepin Healthcare,

Minneapolis, MN
Elizabeth Nelson, MD

Department of Medicine, Hennepin Healthcare, Minneapolis, MN
Jessica Padniewski, DO

Department of Medicine, Hennepin Healthcare, Minneapolis, MN
Rawad Nasr, MD

Rheumatology Division Director, Department of Medicine, Hennepin Healthcare, Minneapolis, MN

\title{
Polymyalgia rheumatica: An updated review
}

\section{ABSTRACT}

Polymyalgia rheumatica should be suspected in older patients with bilateral shoulder and hip stiffness that is worse in the morning and improves with use. An array of nonspecific musculoskeletal complaints, constitutional symptoms, and elevated serum inflammatory markers may be present, so other conditions should also be considered. Prolonged glucocorticoids with patient-tailored dosing and duration are the mainstay of treatment. Corticosteroid-sparing therapy with adjunctive methotrexate may benefit select patients.

\section{KEY POINTS}

Rheumatoid arthritis, late-onset spondyloarthritis, and RS3PE (remitting seronegative symmetrical synovitis with pitting edema) are important mimics of polymyalgia rheumatica.

Diagnosis usually requires either an elevated erythrocyte sedimentation rate (>30 or $40 \mathrm{~mm} / \mathrm{h}$ ) or C-reactive protein level (> $6 \mathrm{mg} / \mathrm{dL})$.

Ultrasonographic evidence of inflammation, especially subacromial bursitis, increases diagnostic specificity.

Patients should be evaluated at diagnosis and periodically for the development of giant cell arteritis.

To help avoid relapse, therapy should continue until symptoms resolve, followed by slow tapering.

Preliminary studies show possible benefit from tocilizumab, an interleukin-6 receptor antibody, as monotherapy or for refractory cases.

doi:10.3949/ccjm.87a.20008
Olymyalgia rheumatica (PMR) is easily recognized when it presents classically, ie, in an older woman with pelvic girdle stiffness that improves over the day, elevated inflammatory markers, and a rapid response to prednisone therapy. But its presentation often overlaps with that of other rheumatologic and inflammatory syndromes.

This article provides guidance on the evaluation and management of PMR and discusses current and emerging therapies.

\section{OLDER ETHNIC EUROPEANS MOST AFFECTED}

PMR typically presents in people over age 50, with incidence increasing with age. Annual incidence varies from 12 to 60 cases per 100,000 in different populations, with the highest rate in those of Northern European descent., ${ }^{1,2}$ Women are more often affected than men.

PMR's etiology is not well understood. Genetic and infectious associations have been investigated without conclusive results. ${ }^{3,4}$ Studies in various geographic regions have revealed increased numbers of certain polymorphisms for genes involved in the immune system, but they have not been consistently found across different populations of patients with PMR. ${ }^{3}$

\section{PROXIMAL BILATERAL MORNING STIFFNESS}

The cardinal feature of PMR is proximal girdle pain associated with restricted range of motion and stiffness. Shoulders are affected in up to 95\% of cases ${ }^{5}$ t the neck and pelvic girdle can also be involved. Patients often report being unable to stand up from a chair, get out of bed without assistance, or lift their arms to comb their hair. 
Bilateral symptoms should particularly raise suspicion for PMR. In some cases, symptoms are unilateral at onset, but quickly become bilateral and often develop rapidly over a few days. ${ }^{4}$

Symptoms are characteristically worse in the morning and with inactivity. Morning stiffness tends to last an hour or more. Pain can also be strikingly severe at night and can affect sleep.

\section{INFLAMMATION MAY BE WIDESPREAD}

Symptoms are related to inflammation of the articular and extra-articular structures, causing synovitis and bursitis of the shoulder, hip, and neck. ${ }^{6}$

Distal joint arthritis may also occur. It is often asymmetric and most commonly affects the knees and wrists, with the feet usually unaffected. ${ }^{6,7}$ Inflammation may also involve periarticular structures, causing distal tenosynovitis and carpal tunnel syndrome. ${ }^{8}$ Pitting edema affecting the distal extremities due to regional tenosynovitis can occur and occasionally is a presenting feature. ${ }^{7}$

Constitutional symptoms (ie, low-grade fever, anorexia, fatigue, and asthenia) are also common, occurring in up to half of patients. ${ }^{9,10}$ However, persistent high fever is uncommon with isolated PMR and may signal the concurrence or development of giant cell arteritis (GCA). ${ }^{11}$

\section{PHYSICAL EXAMINATION: PAIN, LIMITED RANGE OF MOTION}

On physical examination, active range of motion is restricted due to pain, without actual weakness, while passive range of motion may be normal. Muscle tenderness may also be present. $^{10}$

\section{LABORATORY TESTS FOR INFLAMMATION}

Laboratory studies are helpful, as they may indicate an inflammatory state consistent with PMR or, alternatively, suggest or help rule out another diagnosis.

\section{Primary tests: ESR and CRP}

Most established diagnostic criteria for PMR require either elevated erythrocyte sedimentation rate (ESR) (> 30 or $40 \mathrm{~mm} / \mathrm{h}$ ) or elevat- ed C-reactive protein (CRP) $(>6 \mathrm{mg} / \mathrm{dL}),{ }^{12}$ indicating an ongoing inflammatory process. While uncommon, it is possible for levels to be normal; in such cases, rheumatology referral is indicated if PMR is otherwise suspected. ${ }^{13}$

Conversely, elevated levels alone do not establish the diagnosis, as ESR and CRP increase with a variety of conditions, including normal aging.

\section{Other tests may be abnormal}

Other laboratory findings consistent with an ongoing inflammatory process and commonly seen in PMR include normochromic anemia, thrombocytosis, and leukocytosis., ${ }^{4,14}$ Liver enzymes, particularly alkaline phosphatase, may also be elevated. ${ }^{14}$

\section{PMR HAS MANY MIMICS}

Symptoms of PMR may be nonspecific, and many diseases present similarly (Table 1 ).

Rheumatoid arthritis and spondyloarthritis, which may be late-onset, are important considerations. Both can present with distal arthritis, seen in up to half of patients with PMR. ${ }^{5,15}$ As in PMR, joint involvement in rheumatoid arthritis is usually bilateral and symmetric. However, serologic tests for rheumatoid factor and anticitrullinated peptide antibody tend to be positive in rheumatoid arthritis and spondyloarthritis, but not in PMR. Spondyloarthritides are associated with low back pain and stiffness, as well as evidence of sacroiliitis on imaging, which are rare in PMR.

RS3PE (remitting seronegative symmetrical synovitis with pitting edema) involves pitting edema in the distal extremities caused by extensor tendon synovitis, most commonly involving the dorsal surfaces of the hands and wrists. ${ }^{16,17}$ Lower-extremity involvement is much less common. Like PMR, RS3PE responds rapidly to glucocorticoids except when associated with a paraneoplastic syndrome, in which case the underlying malignancy must be treated. ${ }^{18,19}$

Other medium-to-large-vessel vasculitides, including GCA, may also present with unexplained fever and constitutional symptoms. Patients with symptoms of PMR should always be evaluated for signs and symptoms of GCA, including new-onset headache, scalp tenderness, tongue or jaw claudication, and 


\section{TABLE 1}

\section{Key features of polymyalgia rheumatica mimics}

Disease

Inflammatory diseases
Features

\begin{tabular}{|c|c|}
\hline Rheumatoid arthritis & $\begin{array}{l}\text { Symmetrical joint involvement, autoantibody-positive, may see erosions } \\
\text { on imaging in advanced disease }\end{array}$ \\
\hline Spondyloarthritis & Low back involvement, sacroiliac joint tenderness, sacroiliitis on imaging \\
\hline $\begin{array}{l}\text { RS3PE (remitting seronegative symmetrical } \\
\text { synovitis with pitting edema) }\end{array}$ & Peripheral edema, extensor synovitis on imaging, may be paraneoplastic \\
\hline Crystalline arthropathy & $\begin{array}{l}\text { Usually involvement of medium to large joints, intermittent symptoms, } \\
\text { characteristic radiography and ultrasonographic findings, synovial fluid analysis } \\
\text { positive for crystals }\end{array}$ \\
\hline Autoimmune myositis & Muscle weakness and tenderness, elevated muscle enzymes \\
\hline Other connective tissue diseases & $\begin{array}{l}\text { Multiorgan involvement, specific autoantibodies may be positive, } \\
\text { hypocomplementemia }\end{array}$ \\
\hline \multicolumn{2}{|l|}{ Noninflammatory diseases } \\
\hline Osteoarthritis & $\begin{array}{l}\text { Pain exacerbated with use, normal inflammatory markers, degenerative changes } \\
\text { on imaging }\end{array}$ \\
\hline Fibromyalgia & Fatigue, chronic pain with more generalized involvement \\
\hline Spinal spondylosis and stenosis & Numbness, paresthesias, muscle weakness, normal inflammatory markers \\
\hline Parkinson disease & $\begin{array}{l}\text { Muscle stiffness primary complaint, other symptoms typical of Parkinson disease } \\
\text { including tremor and rigidity }\end{array}$ \\
\hline Infection & Fever, heart murmur, leukocytosis, positive blood cultures \\
\hline $\begin{array}{l}\text { Malignancy } \\
\text { and paraneoplastic syndromes }\end{array}$ & $\begin{array}{l}\text { Weight loss, diffuse symptoms usually not limited to shoulder or pelvic girdle, } \\
\text { lack of response to low-dose glucocorticoid therapy }\end{array}$ \\
\hline $\begin{array}{l}\text { Drug-induced myopathy } \\
\text { (eg, statin, glucocorticoid, colchicine) }\end{array}$ & $\begin{array}{l}\text { Lack of systemic symptoms, muscle weakness and tenderness, improvement } \\
\text { with discontinuation of drug, elevated muscle enzymes, positive anti-HMG-CoA } \\
\text { reductase antibody }\end{array}$ \\
\hline Thyroid and parathyroid disease & $\begin{array}{l}\text { Systemic symptoms typical of endocrinopathy; abnormal thyroid markers; } \\
\text { abnormal calcium, phosphorus, or parathyroid levels }\end{array}$ \\
\hline
\end{tabular}

vision changes. If GCA is suspected, temporal artery biopsy should be pursued.

GCA is diagnosed in $16 \%$ to $21 \%$ of patients with PMR, and between 35\% and $50 \%$ of patients with GCA have coexisting PMR. ${ }^{20,21}$ A number of studies have explored genetic features that might link these diseases. Both are associated with certain genetic polymorphisms, particularly those related to the immune system, including genes for human leukocyte antigen and tumor necrosis factor (TNF). However, these associations have not been found consistently. ${ }^{22}$

Noninflammatory syndromes, such as osteoarthritis, spinal stenosis, Parkinson disease, and paraneoplastic asthenia should particularly be suspected if inflammatory markers are absent. $^{4}$ 
Statin-induced muscle toxicity is associated with myalgias and muscle weakness that are usually symmetric, involving the large proximal muscles, particularly of the lower extremities. ${ }^{23}$ Muscle enzymes are frequently elevated, and 3-HMG-CoA reductase antibodies may be positive. ${ }^{23}$ In most cases, discontinuing the drug is sufficient, but if symptoms and muscle enzyme elevation persist, further evaluation for other causes of myopathy and assessment for immune-mediated myopathy are indicated. If the latter is suspected, specialist consultation should be sought, as immunosuppressive treatment may be indicated. ${ }^{24}$

\section{AN EMERGING ROLE FOR ULTRASONOGRAPHY}

Interest has been growing in the use of ultrasonography to help diagnose PMR. Studies have primarily used radiologists and rheumatologists for image acquisition. A number of intraand extra-articular ultrasonographic findings have been associated with PMR, including biceps tenosynovitis, bursitis (subacromialsubdeltoid, ischiogluteal, iliopsoas, and trochanteric), and synovitis (glenohumeral, Presenting coxofemoral, and intervertebral). ${ }^{25}$ However, symptoms: inability to stand up from a chair, get out of bed alone, or lift the arms to comb the hair not all of these findings are specific to PMR or are readily identified. A meta-analysis reported the superior accuracy of diagnosing PMR based on subacromial bursitis vs other areas of inflammation, with unilateral subacromial bursitis having an $80 \%$ sensitivity and $68 \%$ specificity and bilateral subacromial bursitis being $66 \%$ sensitive and $89 \%$ specific. ${ }^{25}$

The PMR classification criteria proposed in 2012 by the European League Against Rheumatism (EULAR) and American College of Rheumatology (ACR) include optional ultrasonographic criteria, allotting a point for either bilateral shoulder pathology or concomitant shoulder and hip findings. ${ }^{11}$ Use of ultrasonographic criteria increases the specificity of the EULAR/ACR classification system from $81.5 \%$ to $91.3 \%{ }^{26}$

Power Doppler ultrasonography allows better assessment of increased blood flow in small blood vessels compared with conventional color Doppler, making it suitable for detecting soft tissue inflammation, as in tendinitis and bursitis. ${ }^{27} \mathrm{~A}$ prospective study of $57 \mathrm{pa}$ - tients with PMR found that a positive power Doppler signal associated with inflammatory shoulder findings at the time of diagnosis was associated with a significantly greater risk of disease relapse than if such findings were $a b$ sent. ${ }^{28}$ However, the same study reported that $60 \%$ of patients continued to have ultrasonographic signs of shoulder inflammation at 6-month follow-up despite being clinically in remission or having low disease activity status, indicating a limited ability of ultrasonography for detecting disease relapse.

\section{TREATMENT OF CHOICE: STEROIDS}

The mainstay of treatment of PMR is oral prednisone therapy. ${ }^{29}$ According to the latest EULAR/ACR guidelines, prednisone therapy should be within the range of 12.5 to $25 \mathrm{mg}$, using the minimum effective dosage to achieve remission. Tapering should be individualized once remission is achieved. ${ }^{30}$

In a randomized controlled trial, Kyle and Hazleman ${ }^{31}$ found that oral prednisone $20 \mathrm{mg} /$ day led to fewer flares than $10 \mathrm{mg} /$ day. The study was limited by small sample size, but this dosage has been noted anecdotally to bring good symptom relief. On the other hand, Kremers et al, ${ }^{32}$ in a retrospective study, found that higher initial corticosteroid doses and faster tapering were significant predictors of future relapse.

Induction dosing should be based on symptom severity, body mass index, and comorbidities. Suggested initial dosing for an average patient is $15 \mathrm{mg} /$ day. Smaller doses (7.5-10 mg daily) can be considered for patients with smaller body habitus, milder symptoms, uncontrolled diabetes, or risk of significant drug adverse effects. For patients with a larger body size or severe symptoms, oral prednisone at 20 to $25 \mathrm{mg}$ per day should be considered.

Treatment should have the goal of symptom remission, as well as improvement and eventual normalization of ESR and CRP levels. ESR and CRP levels typically normalize within 2 to 4 weeks of starting treatment, and normalization is often associated with symptom resolution. ${ }^{29,33}$ If improvements are not evident within 1 to 2 weeks of starting therapy, prednisone should be escalated and alternate diagnoses considered. ${ }^{29,33}$ 
Twice-daily dosing of prednisone (which has a half-life of about 4 hours) has been anecdotally reported to achieve better symptom relief. For patients with difficult-to-control symptoms, this may be helpful, but careful consideration should be taken before recommending this option, given the potential for overdosing and adverse effects.

Dasgupta et $\mathrm{al}^{34}$ explored treating PMR with oral vs intramuscular glucocorticoids in a double-blind study. Both regimens had comparable remission rates. However, because intramuscular therapy has been evaluated only by a single randomized controlled trial, its routine use is discouraged. ${ }^{30}$

Rapid symptomatic improvement in response to low-dose prednisone $(<15 \mathrm{mg})$ historically was regarded as diagnostic for PMR. ${ }^{4}$ However, this response is likely not specific to PMR, as other inflammatory arthritides (eg, rheumatoid arthritis, inflammatory osteoarthritis, crystal arthropathies) may also improve with low-dose prednisone. Conversely, higher dosage requirements may signal another diagnosis, so specialist consultation should be sought if parenteral therapy or twice-daily dosing is being considered.

\section{TREATMENT DURATION AND TAPERING}

Another debated issue is treatment duration, which should generally be patient-specific and symptom-driven. The glucocorticoid dosage that controls symptoms is typically maintained for 2 to 4 weeks after pain and stiffness have resolved. Dosage is then decreased by about 20\% every 2 to 4 weeks, as tolerated, to the minimum amount needed to maintain symptom suppression. ${ }^{35}$ Once a daily prednisone dosage of $10 \mathrm{mg}$ is reached, tapering should be slowed to a rate of $1 \mathrm{mg}$ every 1 to 2 months until discontinuation. ${ }^{35,36}$ Typical treatment lasts 1 to 2 years. Attempting to taper steroids before symptoms resolve or too quickly after symptoms have resolved may result in a higher rate of relapse and decreased success with treatment cessation. ${ }^{36}$

\section{MANAGING RELAPSES}

Relapses and flares should prompt reevaluation of symptoms and laboratory studies for alternate diagnoses. Subsequently, if the patient is still on glucocorticoids, the dosage should be increased by $10 \%$ to $20 \% .^{35}$ For patients whose steroids were successfully discontinued before relapse, induction therapy should be restarted at the lowest effective dose with subsequent taper as tolerated. If symptoms are severe, a single dose of intramuscular methylprednisolone $120 \mathrm{mg}$ can be used to assist with induction therapy. ${ }^{37}$ After 2 relapses, a steroidsparing agent such as methotrexate, azathioprine, a TNF inhibitor, or an interleukin 6 (IL-6) receptor blocker can be tried.

\section{MANAGING CHRONIC STEROID THERAPY}

Adverse effects of chronic glucocorticoid use include skin changes, body composition changes, ocular disorders, cardiovascular disorders (eg, premature atherosclerosis and arrhythmias), gastrointestinal disorders, osteoporosis, mood changes, and renal effects (eg, hypertension). ${ }^{38}$

Patients treated with corticosteroids long-term (> $7.5 \mathrm{mg}$ daily for more than 3 months $)^{39}$ should optimize their vitamin D intake, with supplementation as necessary. Supplementation should be considered for those who cannot tolerate adequate dietary calcium. Bisphosphonate therapy (alendronate or zoledronic acid) should be started as a preventive measure in patients at high risk of fragility fractures, such as elderly patients and patients with a history of fragility fracture. ${ }^{37}$ Others should have their risk factors assessed, and bisphosphonate therapy should be considered for those expected to receive high cumulative glucocorticoid doses, eg, patients who receive a large initial dose.

\section{GLUCOCORTICOID-SPARING THERAPY FOR SOME CASES}

Multiple adjunctive treatments have been explored for PMR.

\section{Methotrexate is standard}

Methotrexate, usually at a starting dosage of 10 to $15 \mathrm{mg}$ per week, is the most commonly used glucocorticoid-sparing therapy for PMR. ${ }^{40} \mathrm{~A}$ double-blind, randomized controlled trial in 40 patients reported no steroid-sparing effect of methotrexate at a dose of $7.5 \mathrm{mg}$ per week. ${ }^{41}$ However, another double-blind randomized

\section{Bilateral symptoms should raise suspicion for PMR}


controlled trial, in 72 patients, showed the addition of methotrexate at $10 \mathrm{mg}$ per week was associated with shorter prednisone treatment, suggesting this approach may be useful for patients at high risk of steroid-related toxicity. ${ }^{42}$ Additionally, a randomized prospective trial in 24 patients reported that the use of subcutaneous methotrexate in a dosage of $10 \mathrm{mg}$ per week allowed for a smaller cumulative prednisone dose over the course of 1 year without loss of efficacy. ${ }^{43}$

Although limited by small sample sizes, these studies suggest that methotrexate can be useful in conjunction with prednisone for specific patient populations, such as the elderly or patients with osteoporosis. The EULAR/ACR guidelines recommend the early introduction of methotrexate therapy in addition to glucocorticoids in patients at high risk for relapse or prolonged therapy and for those who develop glucocorticoid-related adverse effects. ${ }^{30}$

\section{Azathioprine: A possible alternative}

While less studied than methotrexate, azathioprine may also be useful. A double-blind randomized controlled trial ${ }^{44}$ evaluated the use of azathioprine $150 \mathrm{mg}$ daily as adjunctive

Persistent

high fever is uncommon with isolated PMR and may signal giant cell arteritis therapy. The trial enrolled 31 participants diagnosed with PMR, GCA, or both, taking at least $5 \mathrm{mg}$ of daily oral prednisolone to manage symptoms. At the end of 1 year, the group receiving azathioprine were on a lower dose of prednisolone than the placebo group. However, patients with PMR were not separately analyzed, precluding recommending the routine use of azathioprine based on this study. ${ }^{30}$

\section{TNF blockers not recommended}

Tumor necrosis factor (TNF) blockers have been evaluated for PMR as an adjunctive or stand-alone therapy. A 2012 review noted promising results, ${ }^{45}$ but the only randomized controlled trials included (evaluating infliximab and etanercept) failed to meet their primary end points. ${ }^{46,47}$ Hence, TNF blockade is not recommended for managing PMR.

\section{IL-6 blockade is promising}

IL-6 plays a major role in sustaining disease activity in PMR, so IL-6 blockade has been explored as a possible treatment, with promising results. ${ }^{48-50}$

Devauchelle-Pensec et $\mathrm{al}^{51}$ performed a prospective longitudinal study of 20 patients with recent-onset PMR treated with intravenous tocilizumab $8 \mathrm{mg} / \mathrm{kg}$ infusions 3 times at 4-week intervals without glucocorticoids. After week 12 , patients were treated with oral prednisone for 12 weeks. This regimen was found helpful, but the authors concluded that randomized controlled trials are necessary to evaluate it further.

Lally et $\mathrm{al}^{52}$ in an open-label trial in 10 patients who were newly diagnosed with PMR and had been treated with glucocorticoids for less than 1 month, evaluated the efficacy of monthly intravenous tocilizumab $8 \mathrm{mg} / \mathrm{kg}$ for 1 year concurrent with rapid tapering of glucocorticoids. One patient withdrew from the study, but the remaining 9 achieved the primary end point of relapse-free remission at 6 months without glucocorticoids.

Izumi et $\mathrm{al}^{53}$ treated 13 patients who had intractable PMR (significant relapses or little or no response to glucocorticoid treatment) with tocilizumab in addition to their current treatment of prednisolone or methotrexate. They noted significant improvement in PMR symptoms, including morning stiffness, despite decreasing dosage of prednisolone, with no severe adverse effects.

The double-blind, randomized controlled Safety and Efficacy of Tocilizumab Versus Placebo in Polymyalgia Rheumatica With Glucocorticoid Dependence (SEMAPHORE) trial ${ }^{54}$ is currently under way with more than 100 patients.

Although data are still being accumulated, tocilizumab appears to be a promising glucocorticoid-sparing option for treating patients with PMR. However, there are poorly understood risks of long-term use, including possible increases in infections and cardiovascular events. ${ }^{55}$ Therefore, careful consideration is advised before starting IL-6 inhibitors in patients with PMR until more evidence is available.

\section{CLOSE CLINICAL MONITORING}

Regardless of the medication regimen used, patients should be followed closely in the first year after starting treatment, at 0,1 to 3 , and 6 weeks, and at 3, 6, 9, and 12 months. ${ }^{37}$ Additional visits should be arranged as needed for new or worsening symptoms. 


\section{Monitor for GCA development and aortitis}

During follow-up visits, patients should be monitored for symptoms of GCA, including headache, tenderness over temporal arteries, jaw claudication, acute vision loss, and low-grade fever. ${ }^{37}$ GCA and PMR may present together or may be separated in time by long intervals. ${ }^{56}$ Treatment of PMR may not prevent the development of clinical GCA, as the prednisone dosage for PMR is much lower than for GCA, though this is probably rare. ${ }^{57}$
For patients who exhibit signs of GCA, prednisone 40 to $60 \mathrm{mg}$ daily should be promptly started for treatment. ${ }^{58}$

Atypical symptoms, such as unexplained low back pain or symptoms isolated to the lower limbs in association with elevated inflammatory markers should prompt further evaluation for aortitis. ${ }^{59}$ Measurement of bilateral blood pressures and auscultation for bruits should be routinely performed at follow-up.

\section{REFERENCES}

1. Raheel S, Shbeeb I, Crowson CS, Matteson EL. Epidemiology of polymyalgia rheumatica 2000-2014 and examination of incidence and survival trends over 45 years: a population-based study. Arthritis Care Res (Hoboken) 2017; 69(8):1282-1285. doi:10.1002/acr.23132

2. Salvarani C, Macchioni P, Zizzi F, et al. Epidemiologic and immunogenetic aspects of polymyalgia rheumatica and giant cell arteritis in northern Italy. Arthritis Rheum 1991; 34(3):351-356. doi:10.1002/art.1780340313

3. González-Gay MA, Amoli MM, Garcia-Porrua C, Ollier WE. Genetic markers of disease susceptibility and severity in giant cell arteritis and polymyalgia rheumatica. Semin Arthritis Rheum 2003; 33(1):38-48. doi:10.1053/sarh.2002.50025

4. González-Gay MA, Matteson EL, Castañeda S. Polymyalgia rheumatica. Lancet 2017; 390(10103):1700-1712. doi:10.1016/S0140-6736(17)31825-1

5. Chuang TY, Hunder GG, Ilstrup DM, Kurland LT. Polymyalgia rheumatica: a 10-year epidemiologic and clinical study. Ann Intern Med 1982; 97(5):672-680. doi:10.7326/0003-4819-97-5-672

6. Kermani TA, Warrington KJ. Polymyalgia rheumatica. Lancet 2013; 381(9860):63-72. doi:10.1016/S0140-6736(12)60680-1

7. Gonzalez-Gay MA, Garcia-Porrua C, Salvarani C, Hunder GG. Diagnostic approach in a patient presenting with polymyalgia. Clin Exp Rheumatol 1999; 17(3):276-278. pmid:10410257

8. Dasgupta B, Cimmino MA, Kremers HM, et al. 2012 Provisional classification criteria for polymyalgia rheumatica: a European League Against Rheumatism/American College of Rheumatology collaborative initiative. Arthritis Rheum 2012; 64(4):943-954. doi:10.1002/art.34356

9. Salvarani C, Cantini F, Boiardi L, Hunder GG. Polymyalgia rheumatica and giant-cell arteritis. N Engl J Med 2002; 347(4):261-271. doi:10.1056/NEJMra011913

10. Masson C, Gonzalez-Gay MA. Polymyalgia rheumatica and giant cell arteritis. In: Bijlsma JWJ, Hachulla E, eds. EULAR Textbook on Rheumatic Diseases. 2nd ed. London, UK: BMJ Publishing Group; 2015:754-778.

11. Gonzalez-Gay MA, Garcia-Porrua C, Amor-Dorado JC, Llorca J. Fever in biopsy-proven giant cell arteritis: clinical implications in a defined population. Arthritis Rheum 2004; 51(4):652-655. doi:10.1002/art.20523

12. González-Gay MA, Rodríguez-Valverde V, Blanco R, et al. Polymyalgia rheumatica without significantly increased erythrocyte sedimentation rate. A more benign syndrome. Arch Intern Med 1997; 157(3):317-320. doi:10.1001/archinte.1997.00440240081012

13. Jones JG, Hazleman BL. Prognosis and management of polymyalgia rheumatica. Ann Rheum Dis 1981; 40(1):1-5. doi:10.1136/ard.40.1.1

14. Weyand CM, Goronzy JJ. Giant-cell arteritis and polymyalgia rheumatica. Ann Intern Med 2003; 139(6):505-515. doi:10.7326/0003-4819-139-6-200309160-00015

15. Salvarani $\mathrm{C}$, Macchioni PL, Tartoni PL, et al. Polymyalgia rheumatica and giant cell arteritis: a 5-year epidemiologic and clinical study in Reggio Emilia, Italy. Clin Exp Rheumatol 1987; 5(3):205-215. pmid:3501353
16. Salvarani C, Gabriel S, Hunder GG. Distal extremity swelling with pitting edema in polymyalgia rheumatica. Report on nineteen cases. Arthritis Rheum 1996; 39(1):73-80. doi:10.1002/art.1780390110

17. Agarwal V, Dabra AK, Kaur R, Sachdev A, Singh R. Remitting seronegative symmetrical synovitis with pitting edema (RS3PE) syndrome: ultrasonography as a diagnostic tool. Clin Rheumatol 2005; 24(5):476-479. doi:10.1007/s10067-004-1061-x

18. McCarty DJ, O'Duffy JD, Pearson L, Hunter JB. Remitting seronegative symmetrical synovitis with pitting edema. RS3PE syndrome. JAMA 1985; 254(19):2763-2767. pmid:4057484

19. Yao Q, Su X, Altman RD. Is remitting seronegative symmetrical synovitis with pitting edema (RS3PE) a subset of rheumatoid arthritis? Semin Arthritis Rheum 2010; 40(1):89-94. doi:10.1016/j.semarthrit.2008.11.006

20. Gonzalez-Gay MA. Giant cell arteritis and polymyalgia rheumatica: two different but often overlapping conditions. Semin Arthritis Rheum 2004; 33(5):289-293. doi:10.1016/j.semarthrit.2003.09.007

21. Salvarani C, Gabriel SE, O'Fallon WM, Hunder GG. The incidence of giant cell arteritis in Olmsted County, Minnesota: apparent fluctuations in a cyclic pattern. Ann Intern Med 1995; 123(3):192-194. doi:10.7326/0003-4819-123-3-199508010-00006

22. González-Gay MA, Amoli MM, Garcia-Porrua C, Ollier WE. Genetic markers of disease susceptibility and severity in giant cell arteritis and polymyalgia rheumatica. Semin Arthritis Rheum 2003; 33(1):38-48. doi:10.1053/sarh.2002.50025

23. Ward NC, Watts GF, Eckel RH. Statin toxicity. Circ Res 2019; 124(2):328-350. doi:10.1161/CIRCRESAHA.118.312782

24. Selva-O'Callaghan $A$, Alvarado-Cardenas $M$, Pinal-Fernández $I$, et al. Statin-induced myalgia and myositis: an update on pathogenesis and clinical recommendations. Expert Rev Clin Immunol 2018; 14(3):215-224. doi:10.1080/1744666X.2018.1440206

25. Mackie SL, Koduri G, Hill CL, et al. Accuracy of musculoskeletal imaging for the diagnosis of polymyalgia rheumatica: systematic review. RMD Open 2015; 1(1):e000100. doi:10.1136/rmdopen-2015-000100

26. Macchioni P, Boiardi L, Catanoso M, Pazzola G, Salvarani C. Performance of the new 2012 EULAR/ACR classification criteria for polymyalgia rheumatica: comparison with the previous criteria in a single-centre study. Ann Rheum Dis 2014; 73(6):1190-1193. doi:10.1136/annrheumdis-2013-204167

27. Newman JS, Laing TJ, McCarthy CJ, Adler RS. Power Doppler sonog raphy of synovitis: assessment of therapeutic response-preliminary observations. Radiology 1996; 198(2):582-584 doi:10.1148/radiology.198.2.8596870

28. Macchioni P, Catanoso MG, Pipitone N, Boiardi L, Salvarani C. Longitudinal examination with shoulder ultrasound of patients with polymyalgia rheumatica. Rheumatology (Oxford) 2009; 48(12):15661569. doi:10.1093/rheumatology/kep286

29. Gonzalez-Gay MA, Agudo M, Martinez-Dubois C, Pompei O, Blanco R. Medical management of polymyalgia rheumatica. Expert Opin Pharmacother 2010; 11(7):1077-1087. doi: $10.1517 / 14656561003724739$

30. Dejaco C, Singh YP, Perel P, et al; European League Against Rheumatism; American College of Rheumatology. 2015 Recommenda- 
tions for the management of polymyalgia rheumatica: a European League Against Rheumatism/American College of Rheumatology collaborative initiative. Ann Rheum Dis 2015; 74(10):1799-1807. doi:10.1136/annrheumdis-2015-207492

31. Kyle V, Hazleman BL. Treatment of polymyalgia rheumatica and giant cell arteritis. II. Relation between steroid dose and steroid associated side effects. Ann Rheum Dis 1989; 48(8):662-666. doi:10.1136/ard.48.8.662

32. Kremers HM, Reinalda MS, Crowson CS, Zinsmeister AR, Hunder GG, Gabriel SE. Relapse in a population based cohort of patients with polymyalgia rheumatica. J Rheumatol 2005; 32(1):65-73. pmid:15630727

33. Salvarani C, Cantini F, Niccoli L, et al. Acute-phase reactants and the risk of relapse/recurrence in polymyalgia rheumatica: a prospective followup study. Arthritis Rheum 2005; 53(1):33-38. doi:10.1002/art.20901

34. Dasgupta B, Dolan AL, Panayi GS, Fernandes L. An initially doubleblind controlled 96 week trial of depot methylprednisolone against oral prednisolone in the treatment of polymyalgia rheumatica. $\mathrm{Br} J$ Rheumatol 1998; 37(2):189-195. doi:10.1093/rheumatology/37.2.189

35. Weyand CM, Goronzy JJ. Clinical practice. Giant-cell arteritis and polymyalgia rheumatica. N Engl J Med 2014; 371(1):50-57. doi:10.1056/NEJMcp1214825

36. Hernández-Rodríguez J, Cid MC, López-Soto A, Espigol-Frigolé G, Bosch X. Treatment of polymyalgia rheumatica: a systematic review. Arch Intern Med 2009; 169(20):1839-1850. doi:10.1001/archinternmed.2009.352

37. Dasgupta B, Borg F, Hassan N, et al; BSR and BHPR Standards, Guidelines and Audit Working Group. BSR and BHPR guidelines for the management of polymyalgia rheumatica. Rheumatology (Oxford) 2010; 49(1):186-190. doi:10.1093/rheumatology/kep303a

38. Polymyalgia rheumatica: look before you leap. Best Practice J 2013; (53):24-31. Accessed August 16,2020. https://bpac.org.nz/BPJ/2013/ June/docs/BPJ53pages24-31.pdf

39. Hoes JN, Jacobs JW, Boers M, et al. EULAR evidence-based recommendations on the management of systemic glucocorticoid therapy in rheumatic diseases. Ann Rheum Dis 2007; 66(12):1560-1567. doi:10.1136/ard.2007.072157

40. Do-Nguyen D, Inderjeeth CA, Edelman J, Cheah P. Retrospective analysis of the clinical course of patients treated for polymyalgia. Open Access Rheumatol 2013; 5:33-41. doi:10.2147/OARRR.S38443

41. van der Veen MJ, Dinant HJ, van Booma-Frankfort C, van AlbadaKuipers GA, Bijlsma JW. Can methotrexate be used as a steroid sparing agent in the treatment of polymyalgia rheumatica and giant cell arteritis? Ann Rheum Dis 1996; 55(4):218-223. doi:10.1136/ard.55.4.218

42. Caporali R, Cimmino MA, Ferraccioli G, et al; Systemic Vasculitis Study Group of the Italian Society for Rheumatology. Prednisone plus methotrexate for polymyalgia rheumatica: a randomized, double-blind, placebo-controlled trial. Ann Intern Med 2004; 141(7):493-500. doi:10.7326/0003-4819-141-7-200410050-00005

43. Ferraccioli G, Salaffi F, De Vita S, Casatta L, Bartoli E. Methotrexate in polymyalgia rheumatica: preliminary results of an open, randomized study. J Rheumatol 1996; 23(4):624-628. pmid:8730115

44. De Silva M, Hazleman BL. Azathioprine in giant cell arteritis/polymyalgia rheumatica: a double-blind study. Ann Rheum Dis 1986; 45(2):136-138. doi:10.1136/ard.45.2.136

45. Aikawa NE, Pereira RM, Lage L, Bonfá E, Carvalho JF. Anti-TNF therapy for polymyalgia rheumatica: report of 99 cases and review of the literature. Clin Rheumatol 2012; 31(3):575-579. doi:10.1007/s10067-011-1914-z

46. Salvarani C, Macchioni P, Manzini C, et al. Infliximab plus prednisone or placebo plus prednisone for the initial treatment of polymyalgia rheumatica: a randomized trial. Ann Intern Med 2007; 146(9):631639. doi:10.7326/0003-4819-146-9-200705010-00005

47. Kreiner F, Galbo H. Effect of etanercept in polymyalgia rheumatica: a randomized controlled trial. Arthritis Res Ther 2010; 12(5):R176. doi:10.1186/ar3140

48. Martinez-Taboada VM, Alvarez L, RuizSoto M, Marin-Vidalled MJ, Lopez-Hoyos M. Giant cell arteritis and polymyalgia rheumatica: role of cytokines in the pathogenesis and implications for treatment. Cytokine 2008; 44(2):207-220. doi:10.1016/j.cyto.2008.09.004

49. Cutolo M, Montecucco CM, Cavagna L, et al. Serum cytokines and steroidal hormones in polymyalgia rheumatica and elderly-onset rheumatoid arthritis. Ann Rheum Dis 2006; 65(11):1438-1443. doi:10.1136/ard.2006.051979

50. Alvarez-Rodriguez L, Lopez-Hoyos M, Mata C, et al. Circulating cytokines in active polymyalgia rheumatica. Ann Rheum Dis 2010; 69(1):263-269. doi:10.1136/ard.2008.103663

51. Devauchelle-Pensec V, Berthelot JM, Cornec D, et al. Efficacy of firstline tocilizumab therapy in early polymyalgia rheumatica: a prospective longitudinal study. Ann Rheum Dis 2016; 75(8):1506-1510. doi:10.1136/annrheumdis-2015-208742

52. Lally L, Forbess L, Hatzis C, Spiera R. Brief report: a prospective open-label phase lla trial of tocilizumab in the treatment of polymyalgia rheumatica. Arthritis Rheumatol 2016; 68(10):2550-2554. doi:10.1002/art.39740

53. Izumi K, Kuda H, Ushikubo M, Kuwana M, Takeuchi T, Oshima H. Tocilizumab is effective against polymyalgia rheumatica: experience in 13 intractable cases. RMD Open 2015; 1(1):e000162. doi:10.1136/rmdopen-2015-000162

54. US National Library of Medicine. Safety and Efficacy of Tocilizumab Versus Placebo in Polymyalgia Rheumatica with Glucocorticoid Dependence (SEMAPHORE). ClinicalTrials.gov Identifier: NCT02908217. https://clinicaltrials.gov/ct2/show/NCT02908217. Accessed July 7, 2020.

55. Jones G, Panova E. New insights and long-term safety of tocilizumab in rheumatoid arthritis. Ther Adv Musculoskelet Dis 2018; 10(10):195-199. doi:10.1177/1759720X18798462

56. Nesher G, Breuer GS. Giant cell arteritis and polymyalgia rheumatica: 2016 update. Rambam Maimonides Med J 2016; 7(4). doi:10.5041/RMMJ.10262

57. Charlton R. Optimal management of giant cell arteritis and polymyalgia rheumatica. Ther Clin Risk Manag 2012; 8:173-179. doi:10.2147/TCRM.S13088

58. Gonzalez-Gay MA, Martinez-Dubois C, Agudo M, Pompei O, Blanco R, Llorca J. Giant cell arteritis: epidemiology, diagnosis, and management. Curr Rheumatol Rep 2010; 12(6):436-442. doi:10.1007/s11926-010-0135-9

59. Loricera J, Blanco R, Hernandez JL, et al. Non-infectious aortitis: a report of 32 cases from a single tertiary centre in a 4-year period and literature review. Clin Exp Rheumatol 2015; 33(2 suppl 89): S-19-31. pmid:25437450

Address: Rawad Nasr, MD, Division Director, Department of Medicine, Hennepin Healthcare, 701 Park Avenue. S, Minneapolis MN 55415; rawad.nasr@hcmed.org 